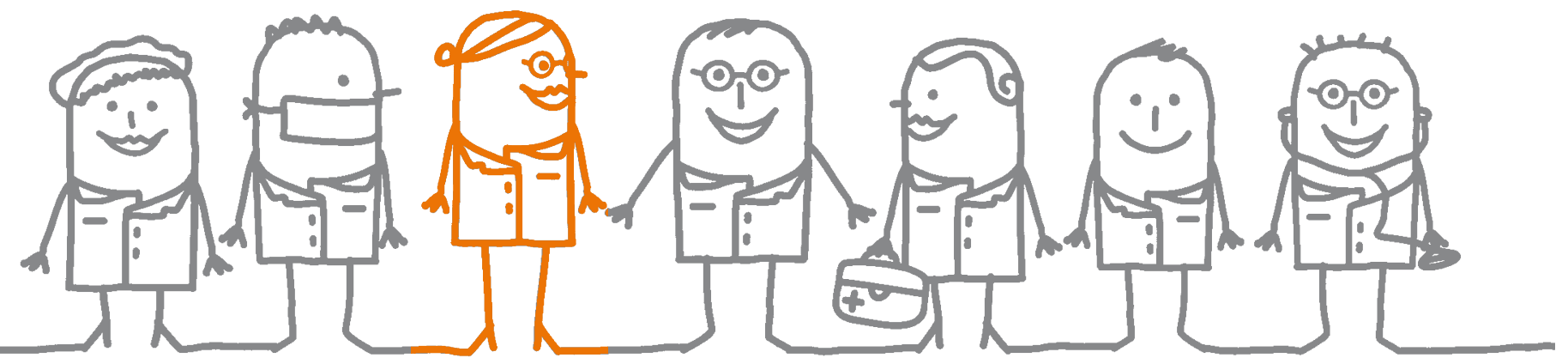

\title{
Gemeinschaftspraxen sind mehr wert als Einzelpraxen
}

\author{
Einzelkämpfer oder Teamplayer? Das ist für niedergelassene Ärzte nicht nur eine Frage der persönlichen Einstellung. \\ Die Praxiskonstellation hat auch Auswirkungen auf die Suche nach einem Nachfolger - und den Praxiswert.
}

$\mathrm{N}$ iedergelassene Ärzte in einer Einzelpraxis sollten die Umwandlung in eine Gemeinschaftspraxis prüfen." Diesen Rat gibt Oliver Frielingsdorf, Geschäftsführer der Frielingsdorf Consult in Köln. „Ein solcher Schritt kann die Erlössituation der Praxis verbessern, ist aber vor allem mit Blick auf einen späteren Verkauf sinnvoll“, so der Praxisberater bei einer Informationsveranstaltung zum Thema „Praxisgestaltung - Kooperationen“ der Münsteraner Kanzlei am Ärztehaus und der Deutschen Apotheker- und Ärztebank (apoBank) Münster/Bielefeld. Noch keine entscheidende Rolle spiele die Organisationsform in Großstädten, in denen es vor allem im fachärztlichen Bereich genügend Interessenten für Arztpraxen gebe. Künftig werde aber auch dort das Szenario vorherrschen, das heute aus ländlichen Regionen bekannt ist: Selbst gut laufende Praxen sind mangels Nachfrage nur schwer abzugeben. Genau in einer solchen Konstellation kann die Praxisform den entscheidenden Unterschied ausmachen.

\section{Sicher in der Gemeinschaftspraxis}

„Die gezahlten Preise für den immateriellen Praxiswert, den Goodwill, sinken, obwohl die Gewinne steigen“, berichtete Frielingsdorf. Der Praxiswert hänge von der Größe und der Struktur des Patientenstamms, der Sicherheit und der Stabilität des Umsatzes sowie der Rentabilität der Praxis ab. Für den Kaufpreis seien neben dem Praxiswert auch das Verhältnis von
Angebot und Nachfrage und die strategischen Interessen des Käufers relevant. Bei den Determinanten des Praxiswerts schneiden nach Angaben von Frielingsdorf Gemeinschaftspraxen meist besser ab. Beim Patientenstamm gelte das allerdings nur, wenn die Partner eine komplementäre Facharztausrichtung haben. „Für jeden einzelnen der Spezialisten wächst der $\mathrm{Pa}$ tientenpool beträchtlich.“

Was den sicheren Umsatz angeht, hält der Praxisberater die Kooperation in jeder Hinsicht für überlegen. Während die Einzelpraxis den Ausfall des Inhabers nur schwer kompensieren wird, könne es in der Gemeinschaftspraxis beispielsweise Vertretungsregelungen geben. Größere Einheiten seien zudem für die Patienten und für mögliche Partner wie Kliniken, Kassen und andere Arztgruppen attraktiver. „Auch bei der Rentabilität gibt es klare Vorteile der Gemeinschaftspraxis. Sie entstehen durch die gemeinsame Nutzung der Infrastruktur, des Personals und von externen Dienstleistern." Für das Verhältnis von Angebot und Nachfrage spiele zwar nach wie vor die Lage der Praxis die entscheidende Rolle, bereits an zweiter Stelle stehe aber das Sicherheitsbedürfnis vieler jüngerer Ärzte. „Die Gemeinschaftspraxis strahlt wesentlich mehr Sicherheit aus", so Frielingsdorf. Hinzu komme, dass durch das Versorgungsstrukturgesetz (VStG) die Zulassungsausschüsse besonder bei Einzelpraxen in überversorgten Städten die Praxisübertragung verhindern können. Hier könnte es eine gute Option sein, die Praxis möglichst bald in eine Kooperation einzubringen, denn: Ist ein Arzt in einer Gemeinschaftspraxis tätig, werden die Zulassungsausschüsse beim Verkauf seines Anteils kaum ein Veto einlegen, da ja auch die Interessen der verbleibenden Eigentümer zu berücksichtigen sind. Lediglich mit Blick auf die strategischen Überlegungen von Käufern wie KlinikMVZ oder Großpraxen könne die Einzelpraxis überlegen sein, weil es Interessenten vor allem um die Zulassung gehe. „Da bietet die Einzelpraxis mehr Flexibilität.“

Kooperative Formen zahlen sich schon heute aus

Für Gemeinschaftspraxen lassen sich schon heute höhere Preise erzielen als für Einzelpraxen, betonte Frielingsdorf. „Durch das VStG weitet sich künftig der Übergabevorteil der Gemeinschaftspraxis auf nahezu alle Fälle und alle Gebiete aus“, prognostiziert der Praxisberater. Nach Daten der apoBank betrugen im Jahr 2010 die durchschnittlichen Übernahmeentgelte pro Sitz bei Orthopäden in Einzelpraxen $158.000 €$ und in Gemeinschafts-praxen $177.000 €$. Bei Gynäkologen waren es $74.000 €$ und $100.000 €$. Mehr als die Hälfte der Ärzte (55\%), die im Zeitraum 2009/2010 eine Existenz als Arzt gegründet haben, haben der apoBank zufolge eine Kooperation als Niederlassungsform gewählt - jedenfalls in den alten Bundesländern.

Ilse Schlingensiepen 